\title{
Hormone-Replacement Therapy and Its Association with Breast Cancer Subtypes: A Large Retrospective Cohort Study
}

\author{
Vered Rosenberg' \\ Avital Bareket-Samish ${ }^{2}$ \\ Gabriel Chodick ${ }^{1,3}$ \\ Nava Siegelmann- \\ Danieli $\mathbb{i D}^{3,4}$
}

\begin{abstract}
'Maccabi Institute for Research and Innovation, Maccabi Healthcare Services, Tel Aviv, Israel; ${ }^{2}$ Biolnsight Ltd, Binyamina, Israel; ${ }^{3}$ Sackler Faculty of Medicine, Tel Aviv University, Tel Aviv, Israel; ${ }^{4}$ Department of Professional Medicine, Maccabi Healthcare Services, Tel Aviv, Israel
\end{abstract}

Purpose: The study examined trends in breast cancer incidence, mammography testing rates, hormone-replacement therapy (HRT) use and breast cancer subtypes in a large Israeli health maintenance organization during 2000-2014.

Methods: Annual rates of mammography tests and HRTs use were analyzed in women age $\geq 45$. Annual incidence rates of breast cancer were analyzed in women age $\geq 20$. Estimated annual percentage changes were used to test changes in incidence rates. Invasive breast cancer subtypes were approximated by treatments received. We compared annual rates and duration of HRTs use between women diagnosed with breast cancer and those who were not, as well as HRT use between subtypes of invasive breast cancer.

Results: We identified 14,092 breast cancer cases ( $88 \%$ invasive, $12 \%$ in situ). The ageadjusted incidence rate of invasive breast cancer peaked in 2005 , consistent with increased mammography screening that year, and decreased thereafter. HRT use decreased from $13.2 \%$ in 2002 to $4.6 \%$ in 2014 . The subtypes distribution of 7771 patients diagnosed with invasive breast cancer during 2007-2014 was: luminal A and B without HER2 over-expression (HR +/HER2-), 69.7\%; Luminal B with HER2 over-expression (HR+/HER2+), 8.9\%; Hormone receptor-negative HER2 enriched (HR-/HER2+), 5.4\%; triple negative (HR-/HER2-), 10.0\%; unknown, $6.0 \%$. Overall, in women age $\geq 45$ diagnosed with invasive breast cancer, $76-86 \%$ did not have HRT exposure vs $14-24 \%$ who were current (within 1 year before the breast cancer diagnosis), recent (within 2-5 years), or past users ( $>5$ years). Current/recent HRT use was statistically significantly higher in luminal vs non-luminal/unknown breast cancer subtypes ( $13.9 \%$ vs $8.9 \%$, respectively; $p<0.001)$.

Conclusion: Our results show a decrease in breast cancer incidence that parallels the global and local decrease in HRT use. Yet, our results imply that current/recent HRT exposure may contribute to the incidence of luminal breast cancer tumors in particular. The magnitude of the effect supports findings from population-based studies.

Keywords: breast cancer, epidemiology, hormone-replacement therapy, incidence, mammography

\section{Introduction}

Globally, breast cancer constitutes the second most common incident cancer in women (after non-melanoma skin cancers) with estimated 1.9 million incident cases and agestandardized incidence rate of 45.9 per 100,000 in $2017 .{ }^{1}$ It is also the leading cause of cancer deaths in women with age-standardized death rate of 14.1 per 100,000 in 2017 . $^{1}$ These rates differ substantially across regions and countries: in 2012, breast cancer
Correspondence: Nava Siegelmann-Daniel Email danieli_na@mac.org.il 
incidence rates ranged from 111.9 per 100,000 (Belgium) to 34.8 per 100,000 (Chile) and 80.5 per 100,000 (Israel). ${ }^{2}$

Breast cancer mortality is being reduced worldwide through mammography screening and improved medical interventions. ${ }^{3,4}$ A meta-analysis of clinical trials demonstrated that over a 10-year period, screening 10,000 women age 50-59 years and 10,000 women age 60-69 is expected to result in 8 and 21 fewer breast cancer deaths, respectively. ${ }^{5}$ The US Preventive Services Task Force recommends biennial screening mammography for average-risk women age $50-74$ years. ${ }^{6}$ The Israeli recommendations follow those issued by the aforementioned task force and a mammography screening program exists in Israel since the early 1990s. ${ }^{7}$

The Women's Health Initiative (WHI) hormone therapy trials included 2 studies involving over 27,000 postmenopausal healthy women, who were randomized to hormone replacement therapy (HRT) or placebo. After the publication of the findings from the estrogen plus progestin trial which reported an increased breast cancer risk with HRT, HRT consumption has decreased in many countries and a subsequent decrease in breast cancer incidence was noted. ${ }^{8-10}$ However, elucidating the role of competing factors such as decreased HRT use and changes in mammography screening on breast cancer incidence has been a challenge. A study conducted in Israel, focusing on women age $\geq 50$ years, demonstrated competing impacts of HRT use and performing mammography tests on breast cancer incidence, with a net decrease in breast cancer incidence associated with reduced HRT utilization. ${ }^{11}$

In the current study, we analyzed trends in mammography testing rates, breast cancer incidence and HRT utilization rates between 2002 and 2014. In addition, we compared annual rates and duration of HRTs use between women diagnosed with breast cancer and those who were not. The association between HRT use and subtypes of invasive breast cancer was assessed as well.

\section{Materials and Methods}

\section{Study Design}

This observational retrospective study utilized the computerized databases of Maccabi Healthcare Services (MHS), a health maintenance organization (HMO) operating in Israel, with over 2 million members, representing a quarter of the Israeli population. MHS databases include person-level data (ie, all data systems are linked by a unique patient identifier) and integrate data from the MHS central laboratory, medication prescriptions and purchases throughout the MHS pharmacy network, consultations, hospitalizations, procedures, and socio-demographic data. Physician diagnoses are coded using the International Classification of Disease, 9th Edition (ICD9-CM) codes as well as by internal MHS codes for subclassification. The study was approved by the institutional review board (IRB) of Bait-Balev Medical Center, and was conducted in accordance with the declaration of Helsinki. The study was granted a waiver for obtaining patient consent.

\section{Study Population and Variables}

The study follow-up period was between January 12002 and December 31 2014. We performed several analyses. For each one, different inclusion criteria were defined (Figure 1).
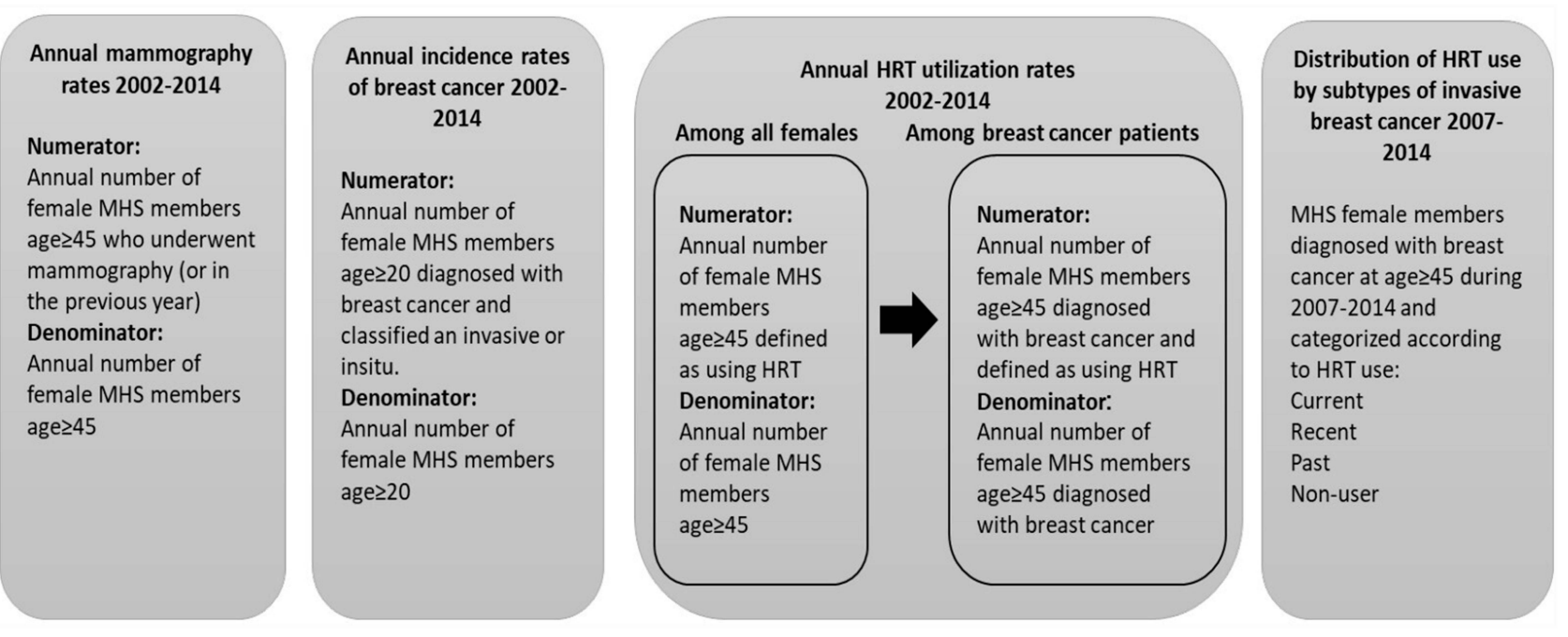

Figure I Study population included in each of the analyses of the study. 
The first analysis examined the annual rates of performing mammography tests during 2002-2014. The numerator included all females age $\geq 45$ years who underwent mammography in a calendar year or the preceding year. The Israeli national program for early breast cancer detection recommends biennial mammography for females age $\geq 50$ years. However, younger women with family history of breast cancer (regardless of their BRCA status) or other medical indication, such as prior biopsy with proliferative changes, are also eligible for mammography. The denominator for each year included all MHS female members who were age $\geq 45$ years.

The second analysis examined the annual incidence rates of breast cancer. Included were MHS female members age $\geq 20$ years, with breast cancer that was first diagnosed during 2002-2014. The breast cancer diagnosis, as identified in the MHS databases was then confirmed through the Israel National Cancer Registry (INCR). Breast cancer was further defined as invasive or in situ according to the INCR code. The annual denominators included all MHS female members age $\geq 20$ years. Subtypes of invasive breast cancer cases were approximated according to treatments received (chemotherapy, hormonal therapy and anti-human epidermal growth factor receptor 2 [HER2] therapy or combination thereof) in the 6 months before the breast cancer diagnosis and up to 18 months after (Table S1). This method, previously described $^{12}$ was used since pathological information is not available electronically. However, in Israel, antiHER2 therapy requires pathological information for approval, as per the guidelines of the American Society of Clinical Oncology. ${ }^{13}$ HR stands for hormone receptor. HR + means that tumor cells have receptors for the hormones estrogen and/or progesterone. HER $2+$ means that tumor cells make high levels the HER2 protein. Invasive breast cancer subtypes were categorized into five groups: luminal $\mathrm{A}$ and luminal $\mathrm{B}$ without HER2 overexpression (HR+ and HER2-); luminal B with HER2 overexpression (HR+ and HER2+); Hormone receptor-negative HER2enriched (HR-and HER2+); triple negative (HR- and HER2-); and the rest were categorized as unknown. ${ }^{14}$ The analysis was restricted to those diagnosed during 2007-2014 as adjuvant trastuzumab was approved in Israel in 2007.

The third analysis examined annual rates of HRT utilization during 2002-2014 in 2 subsets of patients: all female MHS members age $\geq 45$ years and a subset of these members who were diagnosed with breast cancer.
HRT was defined only as oral and transdermal preparations. HRT use was defined similarly in these 2 subsets: in the first subset, the use was defined per calendar year whereas in the second subset, the breast cancer diagnosis date served as a reference date. Current HRT use was defined as use of $\geq 3$ packs of HRTs in a calendar year/ year prior to the breast cancer diagnosis; recent use as no current use and at least one year of use ( $\geq 3$ packs) in years 2-5 before each calendar year/year of breast cancer diagnosis; and past use as no current/recent use and at least one year of use ( $\geq 3$ packs) at least 5 years before the calendar year/year of breast cancer diagnosis. HRT preparations were categorized as those containing estrogen only, estrogen plus progesterone, or tibolone. For breast cancer patients, HRT type category was defined as the last HRT purchase prior to the breast cancer diagnosis. For those with no breast cancer diagnosis, HRT type category was defined as the last HRT purchased during the study follow-up period. Duration of HRT use was defined as the number of years with $\geq 3$ packs of HRTs purchased in a calendar year prior to the breast cancer diagnosis and during the study follow-up period for those with no breast cancer diagnosis.

The fourth analysis examined the distribution of current, recent and past use of HRT by invasive breast cancer subtypes among those age $\geq 45$ diagnosed during 20072014.

\section{Statistical Analyses}

Annual rates of mammography testing and breast cancer incidence are presented per 100,000 patients. Age standardized incidence rates of breast cancer were calculated using the direct method and stratified according to breast cancer type. Estimated annual percentage changes (EAPCs) were determined by fitting a least squares regression to the natural logarithm of the age-adjusted incidence rates during 2002-2014 with 95\% confidence intervals (CI). Annual incidence rates of breast cancer are presented by age groups as well. HRT utilization rates are presented as proportions in all females and in those diagnosed with breast cancer. Chi-square test was used to test differences in the proportions of HRT utilization rates and MannWhitney $U$-test was used to test differences in the duration of HRT use between those diagnosed with breast cancer and non-breast cancer women. Chi-square test was used to test differences in the proportions of HRT utilization rates between luminal subtypes of invasive breast cancer and those with non-luminal/unknown subtypes. 
All statistical analyses were performed with IBM-SPSS version 25.0 standard statistical software. Two-sided $p<0.05$ was considered statistically significant.

\section{Results}

During the study follow-up period, the annual number of female MHS members age $\geq 20$ years, ranged from 500,000 in 2002 to 700,000 in 2014, of whom 200,000-340,000 were $\geq 45$-year-old.

\section{Mammography Testing Rates Over Time}

Overall, mammography testing rates increased from 2002 to 2014. A sharp increase was noted between 2004 and 2005 , from a screening rate of 40,017 per 100,000 to a rate of 48,161 per 100,000 , followed by a steady increase thereafter (Figure S1).

\section{Breast Cancer Incidence by Type and Age Over Time}

Between 2002 and 2014, a total of 14,085 breast cancer cases were identified among MHS female members age $\geq 20$. These cases included 12,354 patients with invasive breast cancer $(87.7 \%$ of incident breast cancer cases) and 1731 patients with in-situ breast cancer $(12.3 \%$ of incident breast cancer cases). The median age at diagnosis for those with invasive breast cancer was 56.0 (IQR 46.065.0) and 54.0 (IQR 47-63) for those diagnosed with insitu breast cancer. The age-adjusted incidence rate of invasive breast cancer peaked in 2005 and decreased thereafter (Figure 2A). The decline for overall breast cancer and for invasive breast cancer was significant (ie, negative EPAC and 95\% CI not crossing the value 0) for the 20022014 period. EAPC $(95 \% \mathrm{CI})$ was $-0.88(-1.37,-0.38)$ overall, $-0.94(-1.42,-0.46)$ for invasive breast cancer and $-0.36(-1.35,0.64)$ for in situ breast cancer. Age is a risk factor for breast cancer overall (Figure 2B), and for invasive and in situ breast cancer separately (Figure S2A and $\mathrm{B}$ ). In women age 50-74, for whom biennial mammography tests are routinely performed at a subsidized price, as part of the national screening program for breast cancer, the invasive breast cancer incidence peaked around 2005, consistent with the mammography increase that year (Figure S1), and declined thereafter (Figure S2A). In patients, age $\geq 75$ years, for whom mammography screening is not routinely performed, no such peak was observed (Figure S2A).

\section{HRT Use and Breast Cancer Incidence Overall and by Subtype}

Analysis of HRT use among all MHS female members (age $\geq 45$ years) by type of use (eg, current and recent users) demonstrated a continuous decrease during 20022014. Specifically, the proportion of current HRT users (ie, use in the calendar year or the year prior to diagnosis) decreased from $13.2 \%$ in 2002 to $4.6 \%$ in 2014 (Figure 3).

Evaluating the proportions of HRT use over time in women diagnosed with breast cancer compared with the non-breast cancer women, demonstrated consistently higher annual rates of current HRT use in those recently diagnosed with breast cancer (Figure 4). In 2003 and as of 2007 the differences between the two groups were significant ( $p<0.05$, Chi-squared test). The median duration of HRTs use was significantly longer among breast cancer patients (5 years, interquartile range [IQR] 2-8) compared with the non-breast cancer women (4 years, IQR 2-7) ( $p<$ 0.001 , Mann-Whitney $U$-test). The proportion of women using HRTs for $\geq 3$ years was $73.3 \%$ among those diagnosed with breast cancer vs $63.0 \%$ among non-breast cancer women ( $p<0.001$, Chi-square test). HRT type used (in women $\geq 45$ years of age) was similar between breast cancer patients and the non-breast cancer women: preparations with estrogen plus progesterone were purchased by $62 \%$ and $61 \%$, estrogen alone by $24 \%$ and $26 \%$, and tibolone by $14 \%$ and $13 \%$, respectively.

\section{Invasive Breast Cancer Subtype and HRT Use}

Between 2007 and 2014, 7771 patients were diagnosed with invasive breast cancer, of whom 6218 were age $\geq 45$ years (Table S2). The distribution of invasive breast cancer subtypes of those age $\geq 45$ was: luminal $A$ and luminal B without HER2 overexpression (HR+ and HER2-), 4548 (73.1\%); luminal B with HER2 over-expression (HR+ and HER2+), 480 (7.7\%); Hormone receptor-negative HER2enriched (HR- and HER2+), 302 (4.9\%); triple negative (HR- and HER2-), 514 (8.3\%); unknown, 374 (6.0\%). We further analyzed HRT use among this subgroup by tumor subtype (Figure 5). Overall, $76.5-86 \%$ of patients age $\geq 45$ across all subtypes did not have any HRT exposure vs 14 $23.5 \%$ who were current, recent, or past users. HRT use in the 5 years before the breast cancer diagnosis (ie, current plus recent use) was statistically significantly higher in those with luminal subtypes vs those with non-luminal /unknown subtypes $(13.9 \%$ vs $8.9 \%, p<0.001$, Chi- 

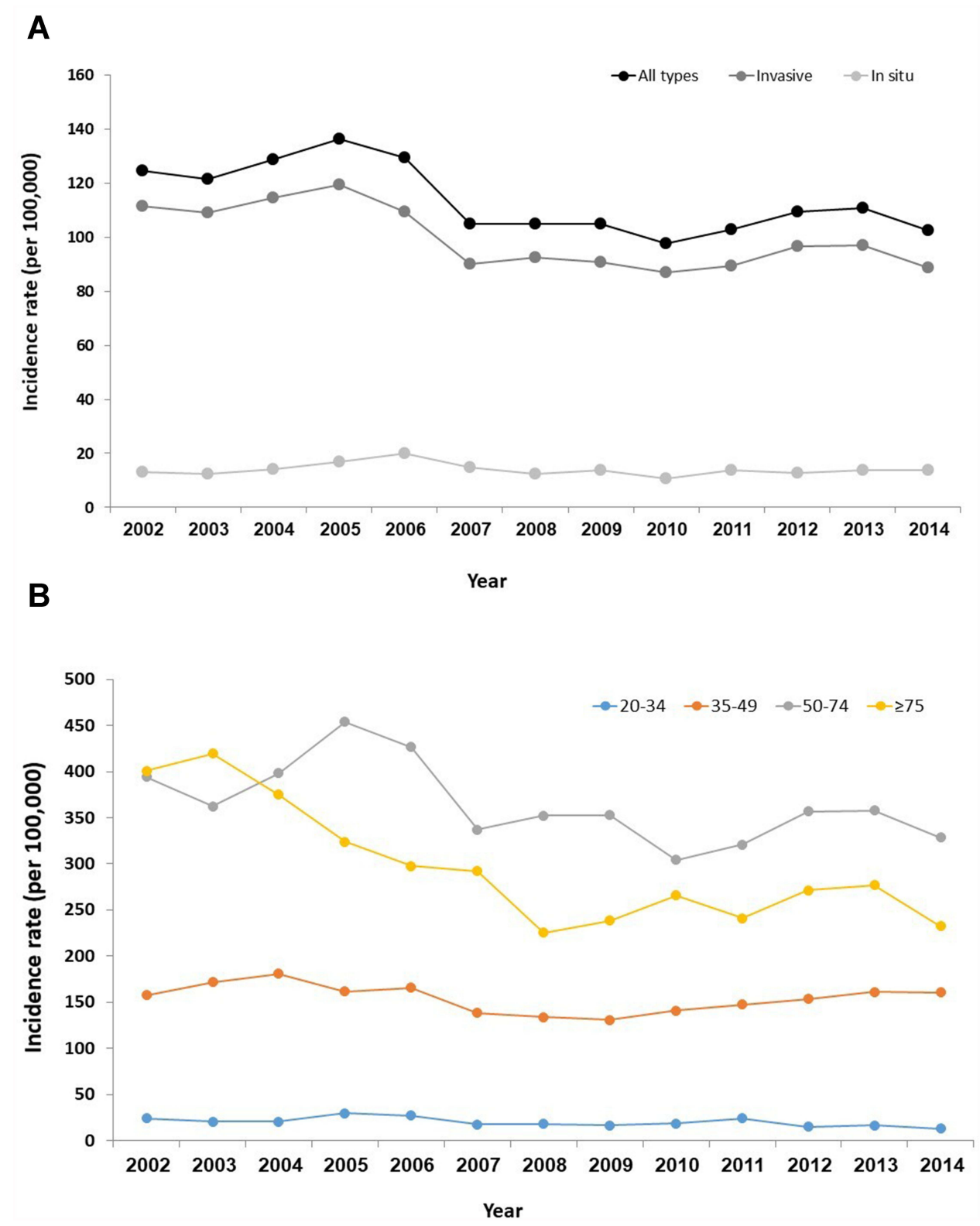

Figure 2 Breast cancer incidence 2002-2014. (A) Age-adjusted annual incidence rate of breast cancer by type and overall. (B) Age-specific annual incidence rates of breast cancer overall (invasive and in situ).

squared test). Specifically, current plus recent HRT use in those with luminal A and luminal B without HER2 overexpression and in those with luminal B with HER2 overexpression was $14.2 \%$ and $11.1 \%$, respectively, whereas in hormone receptor-negative and HER2-enriched, triplenegative, and unknown subtypes, the respective values were $8.9 \%, 9.7 \%$, and $7.7 \%$, (Figure 5).

\section{Discussion}

Our analysis of data from a large HMO with person-level data demonstrated that between 2002 and 2014, HRT use decreased dramatically. Breast cancer incidence also generally decreased over time yet we observed a slight increase in 2005 among women age 50-74 years. This increase may be attributed to intense mammography screening efforts that began in 2004 and reached a peak in 2005. As previously described, ${ }^{11}$ HRT use and mammography have a competing effect on breast cancer incidence, yet our results, together with those of the previous study on MHS database, demonstrate that the decrease in HRT utilization is associated with a decrease in breast cancer incidence. Our results also show higher 


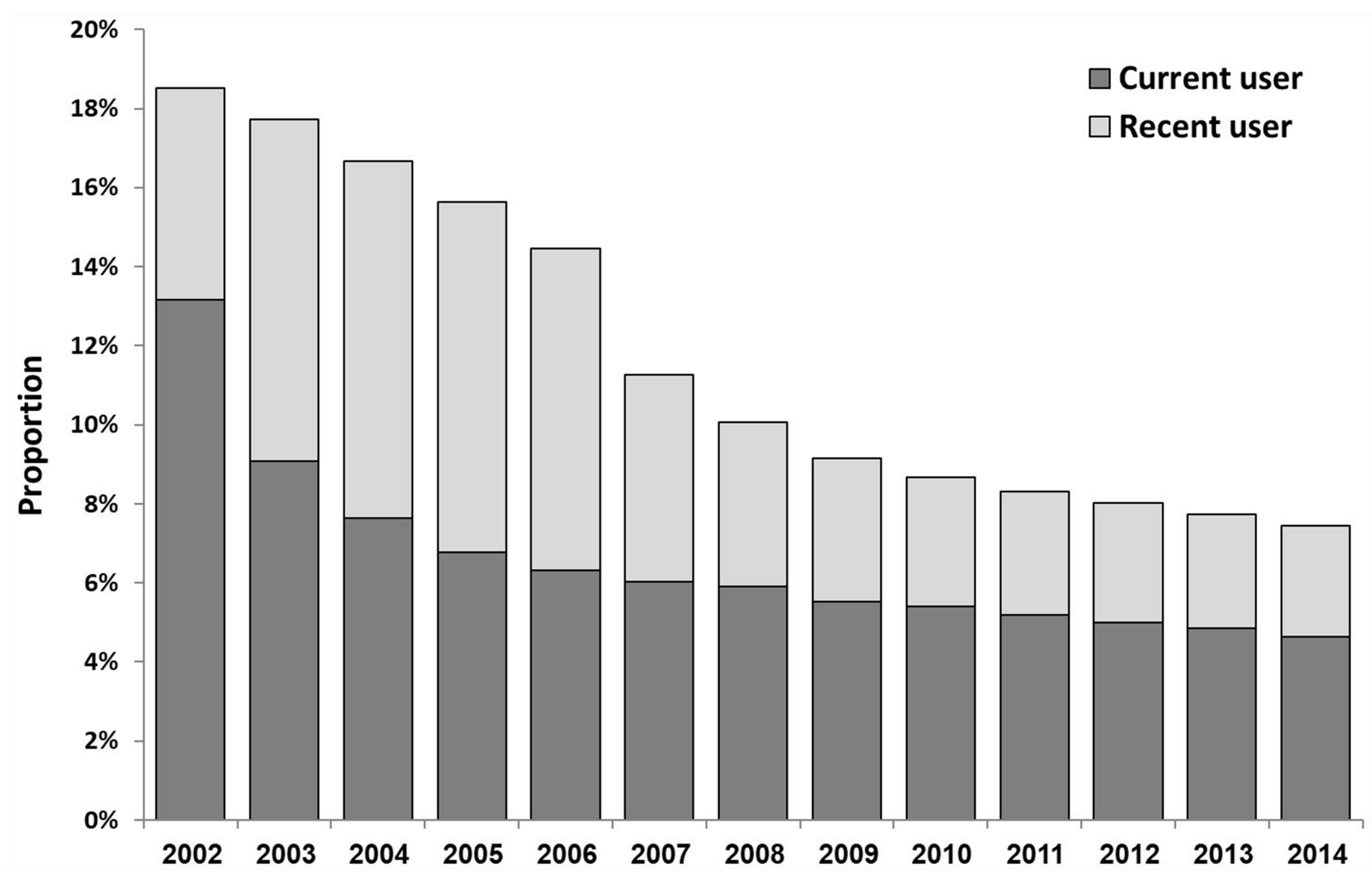

Figure 3 Annual proportions of HRT use 2002-20I4 among all female MHS members (age $\geq 45$ years) by period of use (current users, HRT use in the calendar year/year prior to breast cancer diagnosis; recent users, HRT use in any of the years $2-5$ before each calendar year/year of breast cancer diagnosis).

proportions of current use of HRT and longer duration of HRTs exposure in breast cancer patients compared with non-breast cancer women. The proportion of current/ recent HRT use was significantly higher in women with luminal subtypes than in non-luminal/unknown subtypes, possibly suggesting that HRT use mostly contributes to risk of hormone-dependent tumors.

The observed decrease in breast cancer incidence parallels the decrease in HRT use which is associated with the publication of the data from the WHI hormone therapy trials. This decrease is consistent with findings from numerous observational studies conducted in the US, Canada, Europe, and Australia. ${ }^{15-24}$ This association was also demonstrated by our previous report on HRT use in MHS members. ${ }^{11}$ Moreover, the decrease in breast cancer incidence was observed in the age groups of 50-75 and $\geq 75$ but not among younger women, who do not use HRTs.

The distribution of invasive breast cancer subtypes found in our study is similar to that found by the INCR in 2017 of $85 \%$ luminal subtypes (HR+, with or without HER 2 overexpression) and $10 \%$ triple-negative. ${ }^{25}$ Our distribution is also similar to that found by the United States
National Cancer Institute during 2014-2018 of 68\% HR +/HER2-, $10 \%$ HR+/HER2+, 4\% HER2-enriched, $10 \%$ triple negative and $7 \%$ unknown. ${ }^{14}$

Prior studies have shown that HRT increases breast cancer risk mostly in current (vs never) HRT users, with higher risk for luminal subtypes. ${ }^{8,9,17,20,21,26-33}$ Also, several studies reported that following the decrease in HRT use, the observed decrease in breast cancer incidence was specific to luminal subtypes. ${ }^{17,20,21}$ For example, analysis of the US National Cancer Institute's Surveillance, Epidemiology, and End Results (SEER) registry demonstrated a decrease in breast cancer incidence in women age $\geq 50$ years after 2002 which was more evident in luminal subtypes than in non-luminal subtypes (for women age $50-69$ decrease of $14.7 \%$ vs $1.7 \%$, respectively). ${ }^{17}$ Our results also imply that the association between HRT use within the last 5 years (current/recent) and breast cancer incidence is stronger in luminal subtypes than in nonluminal or other subtypes of breast cancer. Previous studies have also found increased risk for breast cancer among those who used HRT in the 5 years before the breast cancer diagnosis. ${ }^{34,35}$ Notably, the proportion of 


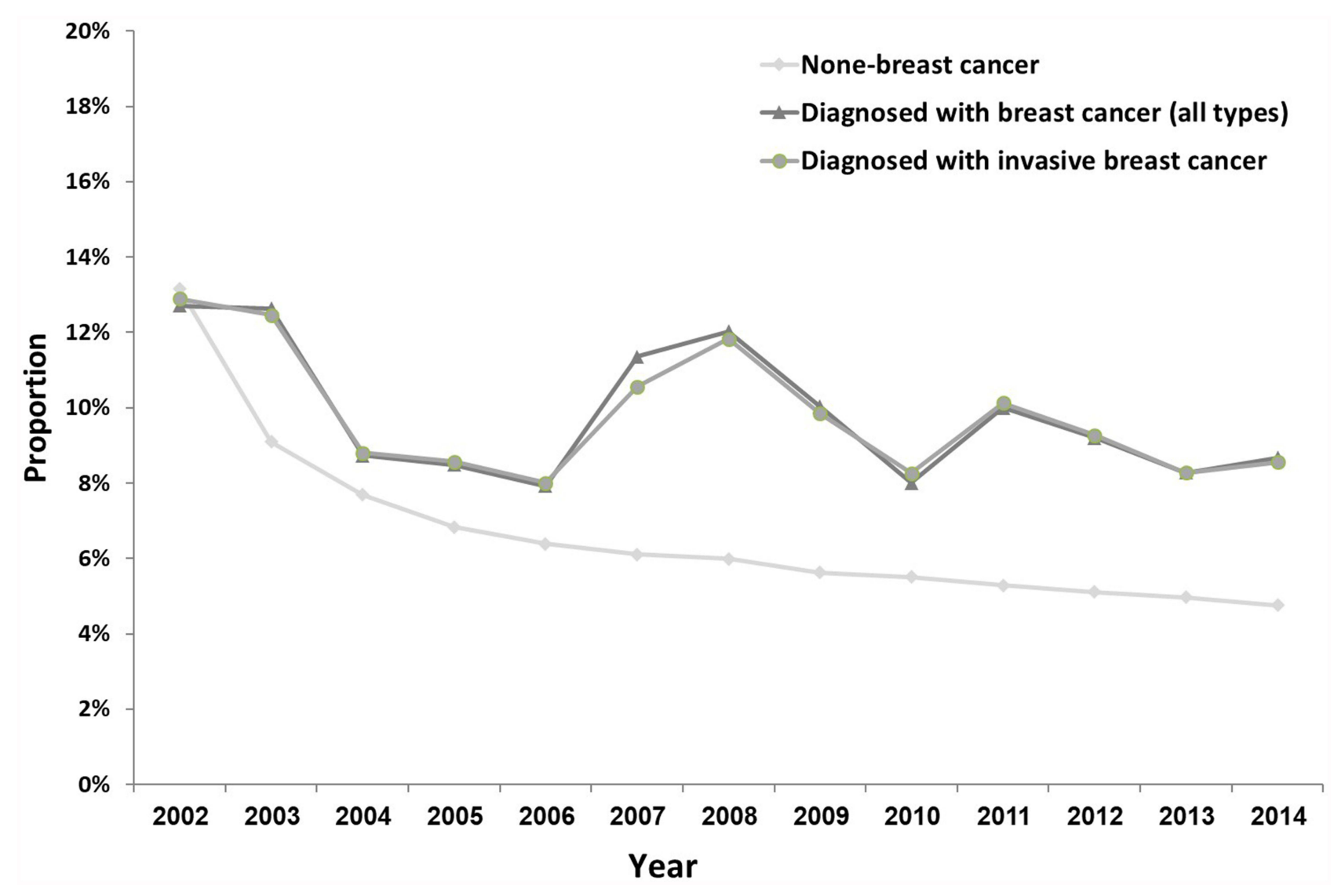

Figure 4 Annual proportions of current use of HRT according to breast cancer status (age $\geq 45$ years). Differences in HRT use between breast cancer free women and those diagnosed with any breast cancer were statistically significant $(p<0.05)$ in 2003 and 2007-20I4.

past users may be underestimated in our analysis, as HRT use has been documented in the MHS systems only from 1998. The proposed biological mechanism behind this association is thought to be the promotion of accelerated growth of existing small carcinomas by HRT (mostly by combined estrogen/progesterone or by androgen), though induction of de-novo malignant tumors cannot be excluded. ${ }^{36}$

The type of HRT used in our study was almost identical in breast cancer and non-breast cancer women purchasing those drugs, and only about a quarter received estrogen-only preparations. The impact of such preparations on breast cancer incidence is still being debated, with recent analyses reporting contradicting results. A metaanalysis on data obtained from 58 studies (approximately 570,000 women) demonstrated that all HRT types except for vaginal estrogens were associated with increased breast cancer incidence and that the greatest risk was with estrogen plus progesterone. ${ }^{35}$ Similarly, the Million Women Study also found in an analysis of approximately 907,000 women that both estrogen only and estrogen plus progesterone preparations were associated with an increased risk for breast cancer mortality. ${ }^{37}$ In contrast, updated findings from the WHI studies involving over 27,000 women, showed that estrogen only preparations were associated with decreased breast cancer incidence, whereas estrogen plus progesterone preparations were associated with increased breast cancer incidence/death. ${ }^{38}$ Also, the duration of HRT use in our study was statistically significantly longer in breast cancer cases than in nonbreast cancer women (medians of 5 vs 4 years, respectively), which is consistent with the findings from the aforementioned meta-analysis and the Million Women Study demonstrating that breast cancer incidence/death increases with duration of HRT use. ${ }^{35,37}$

The strengths of our study include use of real-world data on a large study population. We utilized personal-level data from pharmacy purchasing, mammography tests, and the Israel National Cancer Registry which allowed us to crosslink those diagnosed with breast cancer with their past HRT use, to assess the HRT exposure prior to diagnosis and to compare it to HRT exposure in non-breast cancer women. 


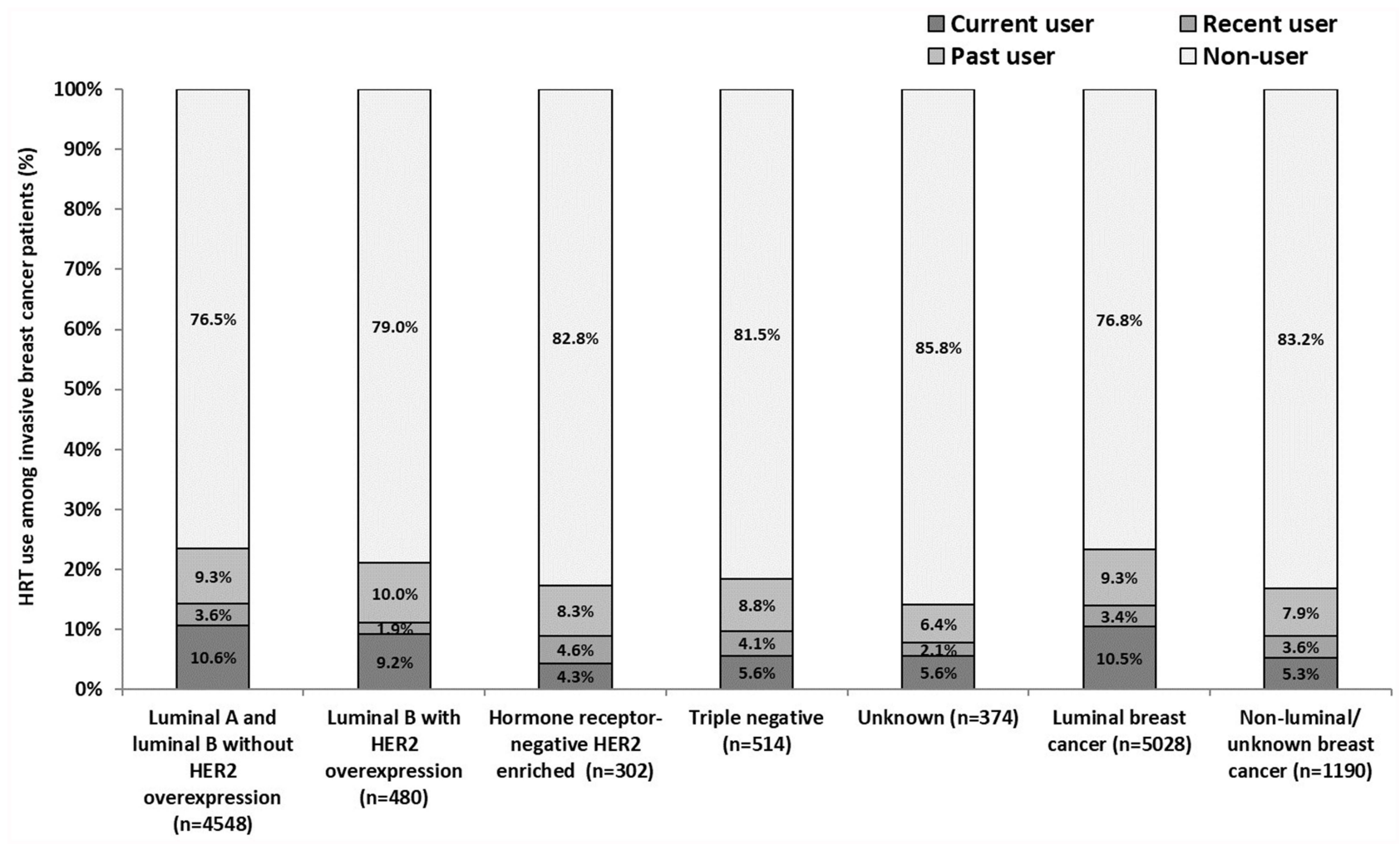

Figure 5 Invasive breast cancer classification and HRT use during 2007-2014 among MHS female members age $\geq 45$ years on diagnosis (n $=6218$ ). The analysis includes current users (within I year prior to the breast cancer diagnosis), recent users (within 2-5 years), past users ( $>5$ years), and non-users.

Abbreviation: HER2, anti-human epidermal growth factor receptor 2.

Our study also has some limitations. Breast cancer subtypes were approximated using actual treatments received, yet a small number of the patients may have not followed clinical treatment recommendations (ie, refused trastuzumab therapy) and their breast cancer subtype may have been misclassified or defined as unknown. Also, HRT use in women with or without breast cancer was assessed only in those aged $\geq 45$ but was not further adjusted for age. Data on BRCA status is considered highly confidential and therefore was unavailable. Lastly, the retrospective nature of our study and the lack of randomization allow us to examine associations but not causation.

\section{Conclusions}

Our analysis on a large-scale HMO personal-level longitudinal data shows a general decrease in breast cancer incidence together with decreased use of HRTs and increased mammography testing rates between 2002 and 2014. The higher proportion of HRTs use among women diagnosed with breast cancer, particularly those with hormone-dependent subtypes, together with the decrease both in invasive breast cancer incidence and in HRT use may indicate a possible association between current/recent HRT use in females age $\geq 45$ years and an increased breast cancer incidence, mostly that of hormonedependent breast cancer tumors.

\section{Data Sharing Statement}

The datasets generated during and/or analyzed during the current study are available from the corresponding author on reasonable request.

\section{Data and Patient Privacy}

The Maccabi Healthcare Services database was accessed by Maccabi's investigators only. The confidentiality of records that could identify subjects within the database was protected, respecting the privacy and confidentiality rules in accordance with the applicable regulatory requirements. Documentation and archiving of this database was implemented. The manuscript includes aggregated data only without any identification.

\section{Ethics Approval}

The study was conducted in accordance with the ICH-GCP, Good Epidemiology Practices (GEP) and Declaration of 
Helsinki, Ethical Principles for Medical Research Involving Human Subjects. The study was conducted per approval of Maccabi Research Committee and the institutional review board (IRB) of Bait-Balev Medical Center.

\section{Consent to Participate}

As this is a retrospective study, the study was granted a waiver for obtaining patient consent.

\section{Acknowledgments}

The abstract of this paper was presented at the 2020 Annual Meeting of the American Society of Clinical Oncology as an online poster presentation with interim findings. The poster's abstract was published in "Poster Abstracts" in the Journal of Clinical Oncology: https://ascopubs.org/doi/ abs/10.1200/JCO.2020.38.15_suppl.e13599.

\section{Author Contributions}

All authors made a significant contribution to the work reported, whether that is in the conception, study design, execution, acquisition of data, analysis and interpretation, or in all these areas; took part in drafting, revising or critically reviewing the article; gave final approval of the version to be published; have agreed on the journal to which the article has been submitted; and agree to be accountable for all aspects of the work.

\section{Funding}

Research and medical writing assistance were funded by Pfizer Pharmaceuticals Israel Ltd.

\section{Disclosure}

ABS is a medical writer contracted by Pfizer. The remaining authors declare no conflicts of interest.

\section{References}

1. Fitzmaurice C, Abate D, Abbasi N, et al.. Global, regional, and national cancer incidence, mortality, years of life lost, years lived with disability, and disability-adjusted life-years for 29 cancer groups, 1990 to 2017: a systematic analysis for the global burden of disease study. JAMA Oncol. 2019;5:1749-1768.

2. Health at a glance 2017: OECD indicators. Available from: http:// www.oecd.org/health/health-systems/health-at-a-glance-19991312. htm. Accessed November 19, 2021.

3. Iwamoto $\mathrm{Y}$, Kaucher S, Lorenz E, Barnighausen $\mathrm{T}$, Winkler $\mathrm{V}$. Development of breast cancer mortality considering the implementation of mammography screening programs - a comparison of Western European countries. BMC Public Health. 2019;19(1):823. doi:10.1186/ s12889-019-7166-6
4. Torre LA, Siegel RL, Ward EM, Jemal A. Global cancer incidence and mortality rates and trends-an update. Cancer Epidemiol Biomarkers Prev. 2016;25(1):16-27. doi:10.1158/1055-9965.EPI-15-0578

5. Siu AL; Force USPST. Screening for breast cancer: U.S. preventive services task force recommendation statement. Ann Intern Med. 2016;164(4):279-296. doi:10.7326/M15-2886

6. U.S. preventive services task force: final recommendation statement. Breast cancer: screening. Available from: https://www.uspreventiveser vicestaskforce.org/Page/Document/RecommendationStatementFinal/ breast-cancer-screening1. Accessed November 19, 2021.

7. Breast cancer in women in Israel - a report on prevalence and mortality in 2018. Available from: https://www.health.gov.i1/ PublicationsFiles/breast_cancer_SEPT2018.pdf. Accessed November 19, 2021.

8. Rossouw JE, Anderson GL, Prentice RL, et al. Risks and benefits of estrogen plus progestin in healthy postmenopausal women: principal results from the women's health initiative randomized controlled trial. JAMA. 2002;288(3):321-333. doi:10.1001/jama.288.3.321

9. Chlebowski RT, Anderson GL, Gass M, et al. Estrogen plus progestin and breast cancer incidence and mortality in postmenopausal women. JAMA. 2010;304(15):1684-1692. doi:10.1001/jama.2010.1500

10. Verkooijen HM, Bouchardy C, Vinh-Hung V, Rapiti E, Hartman M. The incidence of breast cancer and changes in the use of hormone replacement therapy: a review of the evidence. Maturitas. 2009;64 (2):80-85. doi:10.1016/j.maturitas.2009.07.015

11. Silverman BG, Siegelmann-Danieli N, Braunstein R, Kokia ES. Trends in breast cancer incidence associated with reductions in the use of hormone replacement therapy. Cancer Epidemiol. 2011;35 (1):11-16. doi:10.1016/j.canep.2010.11.006

12. Siegelmann-Danieli N, Katzir I, Landes JV, et al. Does levonorgestrel-releasing intrauterine system increase breast cancer risk in peri-menopausal women? An HMO perspective. Breast Cancer Res Treat. 2018;167(1):257-262. doi:10.1007/s10549-0174491-2

13. Giordano SH, Temin S, Chandarlapaty S, et al. Systemic therapy for patients with advanced human epidermal growth factor receptor 2positive breast cancer: ASCO clinical practice guideline update. J Clin Oncol. 2018;36(26):2736-2740. doi:10.1200/JCO.2018.79.2697

14. National Cancer Institute. Cancer Stat Facts: Female Breast Cancer Subtypes 2014-2018. Available from: https://seer.cancer.gov/stat facts/html/breast-subtypes.html. Accessed: 22 Jul 2021

15. Seradour B, Allemand H, Weill A, Ricordeau P. Changes by age in breast cancer incidence, mammography screening and hormone therapy use in France from 2000 to 2006. Bull Cancer. 2009;96(4):E1E6. doi:10.1684/bdc.2009.0869

16. Robbins AS, Clarke CA. Regional changes in hormone therapy use and breast cancer incidence in California from 2001 to 2004. J Clin Oncol. 2007;25(23):3437-3439. doi:10.1200/JCO.2007.11.4132

17. Ravdin PM, Cronin KA, Howlader N, et al. The decrease in breast-cancer incidence in 2003 in the United States. $N$ Engl J Med. 2007;356(16):1670-1674. doi:10.1056/NEJMsr070105

18. Parkin DM. Is the recent fall in incidence of post-menopausal breast cancer in UK related to changes in use of hormone replacement therapy? Eur J Cancer. 2009;45(9):1649-1653. doi:10.1016/j.ejca.2009.01.016

19. Marshall SF, Clarke CA, Deapen D, et al. Recent breast cancer incidence trends according to hormone therapy use: the California Teachers Study cohort. Breast Cancer Res. 2010;12(1):R4. doi: $10.1186 / b c r 2467$

20. Kerlikowske K, Miglioretti DL, Buist DS, Walker R, Carney PA. Declines in invasive breast cancer and use of postmenopausal hormone therapy in a screening mammography population. $J$ Natl Cancer Inst. 2007;99(17):1335-1339. doi:10.1093/jnci/djm111

21. Glass AG, Lacey JV, Carreon JD, Hoover RN. Breast cancer incidence, 1980-2006: combined roles of menopausal hormone therapy, screening mammography, and estrogen receptor status. J Natl Cancer Inst. 2007;99(15):1152-1161. doi:10.1093/jnci/djm059 
22. Clarke CA, Glaser SL, Uratsu CS, Selby JV, Kushi LH, Herrinton LJ. Recent declines in hormone therapy utilization and breast cancer incidence: clinical and population-based evidence. J Clin Oncol. 2006;24(33):e49-50. doi:10.1200/JCO.2006.08.6504

23. Canfell K, Banks E, Moa AM, Beral V. Decrease in breast cancer incidence following a rapid fall in use of hormone replacement therapy in Australia. Med J Aust. 2008;188(11):641-644. doi:10.5694/j.1326-5377.2008.tb01821.x

24. De P, Neutel CI, Olivotto I, Morrison H. Breast cancer incidence and hormone replacement therapy in Canada. J Natl Cancer Inst. 2010;102(19):1489-1495. doi:10.1093/jnci/djq345

25. Breast cancer in women in Israel. Available from: https:/www.health. gov.i1/PublicationsFiles/breast_cancer_sept2020.pdf. Accessed Nov ember 19, 2021.

26. Salagame U, Banks E, O’Connell DL, Egger S, Canfell K. Menopausal hormone therapy use and breast cancer risk by receptor subtypes: results from the New South Wales Cancer Lifestyle and EvaluAtion of Risk (CLEAR) study. PLoS One. 2018;13(11): e0205034. doi:10.1371/journal.pone.0205034

27. Ellingjord-Dale M, Vos L, Tretli S, Hofvind S, Dos-Santos-Silva I, Ursin G. Parity, hormones and breast cancer subtypes - results from a large nested case-control study in a national screening program. Breast Cancer Res. 2017;19(1):10. doi:10.1186/s13058-016-0798-x

28. Kumle M. Declining breast cancer incidence and decreased HRT use. Lancet. 2008;372(9639):608-610. doi:10.1016/S0140-6736(08) 61255-6

29. Canfell K, Banks E, Clements M, et al. Sustained lower rates of HRT prescribing and breast cancer incidence in Australia since 2003. Breast Cancer Res Treat. 2009;117(3):671-673. doi:10.1007/ s10549-009-0331-3

30. Saxena T, Lee E, Henderson KD, et al. Menopausal hormone therapy and subsequent risk of specific invasive breast cancer subtypes in the California Teachers Study. Cancer Epidemiol Biomarkers Prev. 2010;19(9):2366-2378. doi:10.1158/1055-9965.EPI-10-0162
31. Chen WY, Hankinson SE, Schnitt SJ, Rosner BA, Holmes MD, Colditz GA. Association of hormone replacement therapy to estrogen and progesterone receptor status in invasive breast carcinoma. Cancer. 2004;101(7):1490-1500. doi:10.1002/cncr.20499

32. Beral V, Reeves G, Bull D, Green J; Million Women Study C. Breast cancer risk in relation to the interval between menopause and starting hormone therapy. J Natl Cancer Inst. 2011;103(4):296-305. doi:10.1093/jnci/djq527

33. Setiawan VW, Monroe KR, Wilkens LR, Kolonel LN, Pike MC, Henderson BE. Breast cancer risk factors defined by estrogen and progesterone receptor status: the multiethnic cohort study. Am $J$ Epidemiol. 2009;169(10):1251-1259. doi:10.1093/aje/kwp 036

34. Vinogradova Y, Coupland C, Hippisley-Cox J. Use of hormone replacement therapy and risk of breast cancer: nested case-control studies using the QResearch and CPRD databases. BMJ. 2020;371: m3873. doi:10.1136/bmj.m3873

35. Collaborative Group on Hormonal Factors in Breast C. Type and timing of menopausal hormone therapy and breast cancer risk: individual participant meta-analysis of the worldwide epidemiological evidence. Lancet. 2019;394(10204):1159-1168. doi:10.1016/S01406736(19)31709-X

36. Dietel M, Lewis MA, Shapiro S. Hormone replacement therapy: pathobiological aspects of hormone-sensitive cancers in women relevant to epidemiological studies on HRT: a mini-review. Hum Reprod. 2005;20(8):2052-2060. doi:10.1093/humrep/dei043

37. Beral V, Peto R, Pirie K, Reeves G. Menopausal hormone therapy and 20-year breast cancer mortality. Lancet. 2019;394(10204):1139. doi:10.1016/S0140-6736(19)32033-1

38. Chlebowski RT, Anderson GL, Aragaki AK, et al.: Long-term influence of estrogen plus progestin and estrogen alone use on breast cancer incidence: the Women's Health Initiative randomized trials. Abstract GS5-00. San Antonio, TX: San Antonio Breast Cancer Symposium (SABCS); 2019.

\section{Publish your work in this journal}

The International Journal of Women's Health is an international, peerreviewed open-access journal publishing original research, reports, editorials, reviews and commentaries on all aspects of women's healthcare including gynecology, obstetrics, and breast cancer. The manuscript management system is completely online and includes a very quick and fair peer-review system, which is all easy to use. Visit http://www.dovepress.com/testimonials.php to read real quotes from published authors. 